\title{
Connections in the development of tropical cyclone Mitch (1998): A tribute to the human loss in this calamity
}

\author{
Ismael PÉREZ-GARCÍA ${ }^{\dagger}$, Alejandro AGUILAR-SIERRA* and Jaime Steven HERNÁNDEZ-ALFARO \\ Centro de Ciencias de la Atmósfera, Universidad Nacional Autónoma de México, Circuito de la Investigación Cientifica s/n, \\ Ciudad Universitaria, 04510 Ciudad de México, México \\ Corresponding author; email: asierra@unam.mx
}

Received: April 6, 2017; accepted: May 9, 2018

\begin{abstract}
${ }^{\dagger}$ Dr. Ismael Pérez-García, a great meteorologist, scientist, and teacher passed away on April 20, a few days before the acceptance of this paper, in which he worked during his last days. This paper is a tribute to the victims of Mitch, but also to the life and work of Ismael Pérez-García.
\end{abstract}

\begin{abstract}
RESUMEN
Se estudia el ciclón tropical Mitch, que ocurrió en el mar Caribe en octubre de 1998. Mitch afectó a varios países de Centroamérica, donde causó grandes pérdidas humanas y económicas, y los autores consideran que la comunidad científica no le ha otorgado la atención que requiere. Dos patrones dipolares con orientación NE-SE asociados con sus zonas de convergencia-divergencia contribuyeron significativamente a su formación e intensificación, las cuales se analizan desde el punto de vista sinóptico observacional. Las características más notables de este fenómeno en el campo medio ocurrieron entre el 18 de octubre y el 4 de noviembre de 1998, cuando se formó otro patrón dipolar con dirección NO-SE, conformado por un anticiclón de Norteamérica de niveles altos (HLA, por sus siglas en inglés) y un anticiclón de Sudamérica de niveles altos (HLC, por sus siglas en inglés). Para discernir estos patrones se utilizaron dos fuentes de datos: el reanálisis NCAR-ds627.0 (ERA-Interim) y el de NCEP/NCAR. La idealización más simple de un vórtice dipolar NO$\mathrm{SE}$ es un modón tropical, que es una solución exacta de la ecuación de vorticidad barotrópica (BVE, por sus siglas en inglés) en una esfera en rotación. Se explora el papel del HLA y el HLC en la excitación de las ondas tropicales utilizando un método espectral numérico para estudiar el modo de estabilidad normal de las soluciones exactas de la BVE. La iniciación de la onda tropical en niveles bajos podría estar asociada con perturbaciones en niveles altos del modo normal más inestable.
\end{abstract}

\section{ABSTRACT}

Tropical cyclone Mitch, which occurred in October 1998 on the Caribbean Sea, is studied. Mitch affected countries in Central America, where it caused great economic and human losses, and the authors believe that the scientific community has not paid enough attention to this phenomenon. Two NE-SE oriented dipole patterns associated with their convergence-divergence zones contributed significantly to its formation and intensification, which are analyzed from the observational synoptic point of view. The most remarkable characteristics of this phenomenon in the mean field occurred between October 18 and November 4, 1998 when another NW-SE dipolar pattern was formed, consisting of a high-level anticyclone from North America (HLA) and a high-level anticyclone from South America (HLC). To discern these patterns, two data sources were used: the NCAR-ds627.0 (ERA-Interim) reanalysis and the NCEP/NCAR reanalysis. The simplest idealization of the NW-SE dipolar vortex is a tropical modon, which is an exact solution of the barotropic 
vorticity equation (BVE) on a rotating sphere. The role of the HLA and the HLC in the excitation of tropical waves is explored using a numerical spectral method for sutdying the normal mode stability of exact solutions of the BVE. The initiation of the tropical wave at low levels could be associated with disturbances at high levels of the most unstable normal mode.

Keywords: Tropical cyclone Mitch, La Niña, transient connection patterns, tropical wave, barotropic vorticity equation, Verkley's modon solution, normal mode instability.

\section{Introduction}

The coasts of Mexico and Central America are affected by tropical cyclones of the north Atlantic and the northeast Pacific. The relationship between El Niño-Southern Oscillation (ENSO) and the tropical cyclones of the Northeast Pacific and the North Atlantic has been studied by many authors (Landsea, 1993; Demaria and Kaplan, 1994; Goldenberg et al., 2001; Vitart and Anderson, 2001; Amador et al., 2006; Camargo et al., 2007; Wood and Ritchie, 2013). Gray (1984) and Shapiro (1987) point out that the smaller vertical shear that accompanies La Niña phase directly contributes to increasing the number of tropical cyclones in the Atlantic. Camargo et al. (2007) noted that tropical cyclone activity decreased in the Atlantic during El Niño years.

In this paper, we show that large horizontal convergences are generated at higher levels during La Niña phase near the central-eastern Pacific, which can suppress the activity of tropical cyclones in this region due to the vertical shear. In section 2, we look more closely at how the tropical waves are amplified by the tropical upper tropospheric trough (TUTT).

Gray (1984) suggests that El Niño can suppress hurricane activity in tropical Atlantic regions due to its influence in the upper troposphere; however, he also indicates that the summer TUTT will act as a process to decrease the inhibitory influences of the vertical shear and the ventilation of higher levels over the center of a disturbance. In section two, we will look more closely at the way in which tropical waves are amplified by the TUTT. It is not clear which physical mechanisms are responsible for the greater number and intensity of hurricanes during La Niña years, although it has been observed that the trajectories of tropical cyclones are mainly towards the west during these periods, tending to recurve during E1 Niño years.

The first part of this study, presented in section 2 , focuses on the La Niña period of 1998, with a particular emphasis on the study of the development of tropical cyclone Mitch in the Caribbean sea. Our basic idea is based on the fact that during a La Niña phase, a large-scale convergence can be created near Central America. Mitch's general movement was slow, resulting in a large amount of rainfall, mainly in Central America, where it caused catastrophic losses and devastation, especially in Honduras, El Salvador, Guatemala and Nicaragua (Hellin and Haigh, 1999; Lidy et al., 2001; Pasch et al., 2001). Although tropical cyclone Mitch caused widespread damage, the scientific community has not studied it extensively.

The relationships observed between low pressure and the number of tropical cyclones in the Caribbean Sea show peaks in June and October (Inoue et al., 2002), and in the last month there is a weak easterly wind and a sea level pressure (SLP) minimum (Wang, 2007). In the lower troposphere, tropical waves appear as an inverted "V" and move along with the trade winds across the Atlantic Ocean (Frank, 1968). They begin to appear from April/May and continue until October/November (Burpee, 1972). It has been recognized that around $60 \%$ of Atlantic tropical storms originate from the eastern waves and that almost all tropical cyclones that occur in the eastern Pacific Ocean can also be traced from Africa (Burpee, 1972; Avila and Pasch, 1995). Burpee (1972) documented a mechanism for the origin of these waves, the instability of the east African jet. Although other characteristics were proposed (Krishnamurti et al., 2013), here we suggest that tropical systems are disturbed by the instability of a dipolar vortex in the upper troposphere, which is first examined by means of observations and then by the analysis of eigenvalues of the non-divergent linearized barotropic vorticity equation. So, some of the basic aspects of the development and movement of tropical cyclone Mitch can be illustrated in terms of the barotropic vorticity equation (BVE) theory over the sphere. 
The present work provides an observational study of a dipolar vortex in the upper troposphere associated with tropical cyclone Mitch; these dipolar vortices have not been documented in the literature (PérezGarcía et al., 2017). Tropical cyclone Mitch was not an isolated solitary vortex but it was pushed by a directional flow generated within a dipolar vortex of the upper troposphere. Our challenge is to understand in how many ways the environment interacted with Mitch. The dipolar vortex could have helped to intensify the cyclone and move it towards the SW (PérezGarcía et al., 2017). This environment is the dipolar vortex of the upper troposphere on a large scale and can be analytically represented by a Gill solution (Gill, 1980) or an exact solution of the non-linear BVE. The structure is very similar to a modon trapped near the equator (Verkley, 1984; Pérez-García and Skiba, 1999; Skiba and Pérez-García, 2009). In the context of the BVE exact solutions on the rotating unit sphere, a dipolar vortex of the upper troposphere is constructed and is called the tropical modon. The modons are localized solutions of nonlinear dynamic equations. They are stable against interactions with external fields (Leith, 1981) and are obtained without the existence of a local source of warming.

Despite its simplicity, this BVE contains the main elements that describe the complexity of atmospheric behavior (Simmons et al., 1983; Pérez-García et al., 2016) and provides information on tropical circulation. This has not been previously examined in the literature. Our modest goal is to fill this gap for the equatorial waves of non-linear basic dynamics. This is first presented observationally in section 2 and then analytically in section 3 . The concluding remarks are given in section 4 .

\section{Transient connection pattern and tropical cir- culation during tropical cyclone Mitch, 1998}

Many tropical disturbances drive large amounts of clouds by low-level air convergence; therefore, the wind field provides more information about tropical circulation than pressure. For this investigation, NCAR-ds627.0 (ECMWF, 2009) and NCEP/NCAR reanalysis data (Kalnay et al., 1996) were used. In particular, we used the relative humidity and the zonal $(u)$ and meridional $(v)$ components of the wind field at different pressure levels. These wind components were used to calculate the divergence $\delta$, the vertical component of the relative vorticity $\zeta$, the stretch deformation $E$ and the shear deformation $F$. To obtain a clear view of the entire circulation over the tropical region, we took the whole sphere as domain.

The term $(u, v)$ is decomposed into a non-divergent flow and an irrotational flow. The non-divergent flow is described by the stream function $\psi$, which satisfies $\nabla^{2} \psi=\zeta$, and the irrotational flow satisfies $\nabla^{2} \chi=\delta$, where $\chi$ is the velocity potential. These elliptic equations are solved using the numerical spectral method (Sardeshmukh and Hoskins, 1987) where we use a grid of $128 \times 64$ and a truncation of T31.

Figure 1a shows the relative humidity in the 700$925 \mathrm{hPa}$ layer and the average streamlines for the upper layer (200-300 hPa) on October 16, 1998 at 12 UTC. The interesting feature in this field that passes over the tropical American region is the dipolar envelope that contains two vortices; one is the high-level anticyclone from South America (HLC), and the other is the high-level anticyclone from North America (HLA) (Reed, 1933). Two trough lines referred to as TUTT and small cyclone (C1) and anticyclone (A1) can also be seen in Figure 1a.

Figure $1 \mathrm{~b}$ shows the average streamlines for the lower layer (925-1000 hPa) and the relative humidity (for the 700-925 hPa layer, shaded) for October 17, 1998 at 00 UTC. A longitudinal band of eastern zonal wind was located at the south of the Gulf of Mexico, induced by a transient anticyclone labeled as TA and a zonal wind traced to the central Atlantic caused by the southern edge of the North Atlantic Subtropical High (NASH). As the eastern zonal wind continued to the Americas, some streamlines are directed toward Mexico-Central America and other streamlines to South America. As the eastern wind continued to flow into the Caribbean Sea, a tropical wave associated to the origin of Mitch is not present in the streamlines.

Figure 2a shows the GOES-IR satellite images for the same date (October 17) at 00 UTC, where we can see that a cloud cluster associated with the development of the tropical wave was not yet noticeable, only a cover of clouds to the east is observed. On October 18 at 23:45 UTC, a cloud cluster was seen in the vicinity of $60 \mathrm{~W}, 15 \mathrm{~N}$ (Fig. 2b). Comparing Figure 1b with Figure 2a, 2b, that cloud cluster embedded in an easterly wind is easier to track than a tropical wave (Sikdar and Hentz, 1980). 


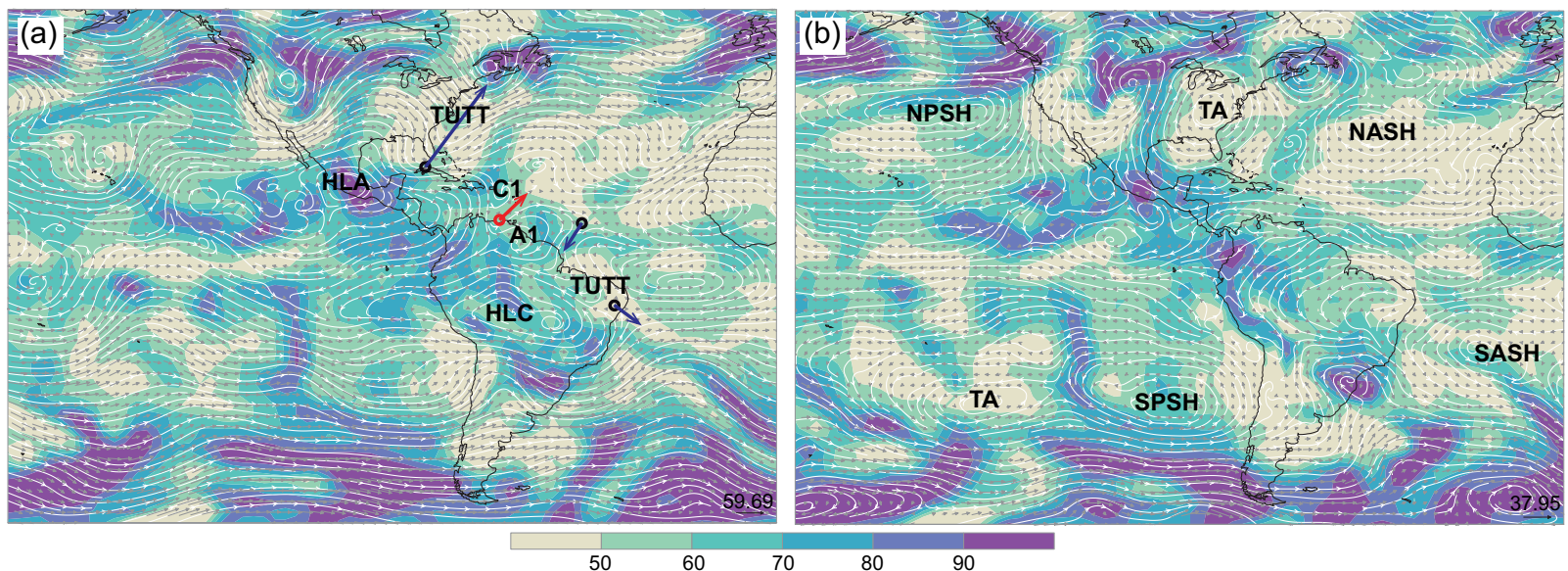

Fig. 1. (a) Mean streamlines for the upper layer (200-300 hPa) and mean relative humidity (shaded) in the 700-925 hPa layer for October 16, 1998 at 12 UTC. The high-level anticyclone of North America (HLA), the high-level anticyclone (HLC) of South America, the cyclone C1 and the small anticyclone A1 are designed. The bold arrows (red and blue) indicate the small jet cores and the tropical upper tropospheric troughs (TUTT) are designated by a thin blue arrow. (b) Streamlines and winds of the 925-1000 hPa layer and mean RH of 700-925 hPa (shaded) for October 19, 1998 at 00 UTC. HR areas greater than 50\% in (a) are indicated by darker shades, the contour interval for $50-100 \%$ is 10 , white shading indicates values below $50 \%$. The maximum wind intensity $(\mathrm{m} / \mathrm{s})$ is labeled on the lower right corner. Transient anticyclones are labeled as TA, northeast and southeast Pacific subtropical highs as NPSH and SPSH, respectively, as well as NASH and SASH for North Atlantic and South Atlantic subtropical highs.
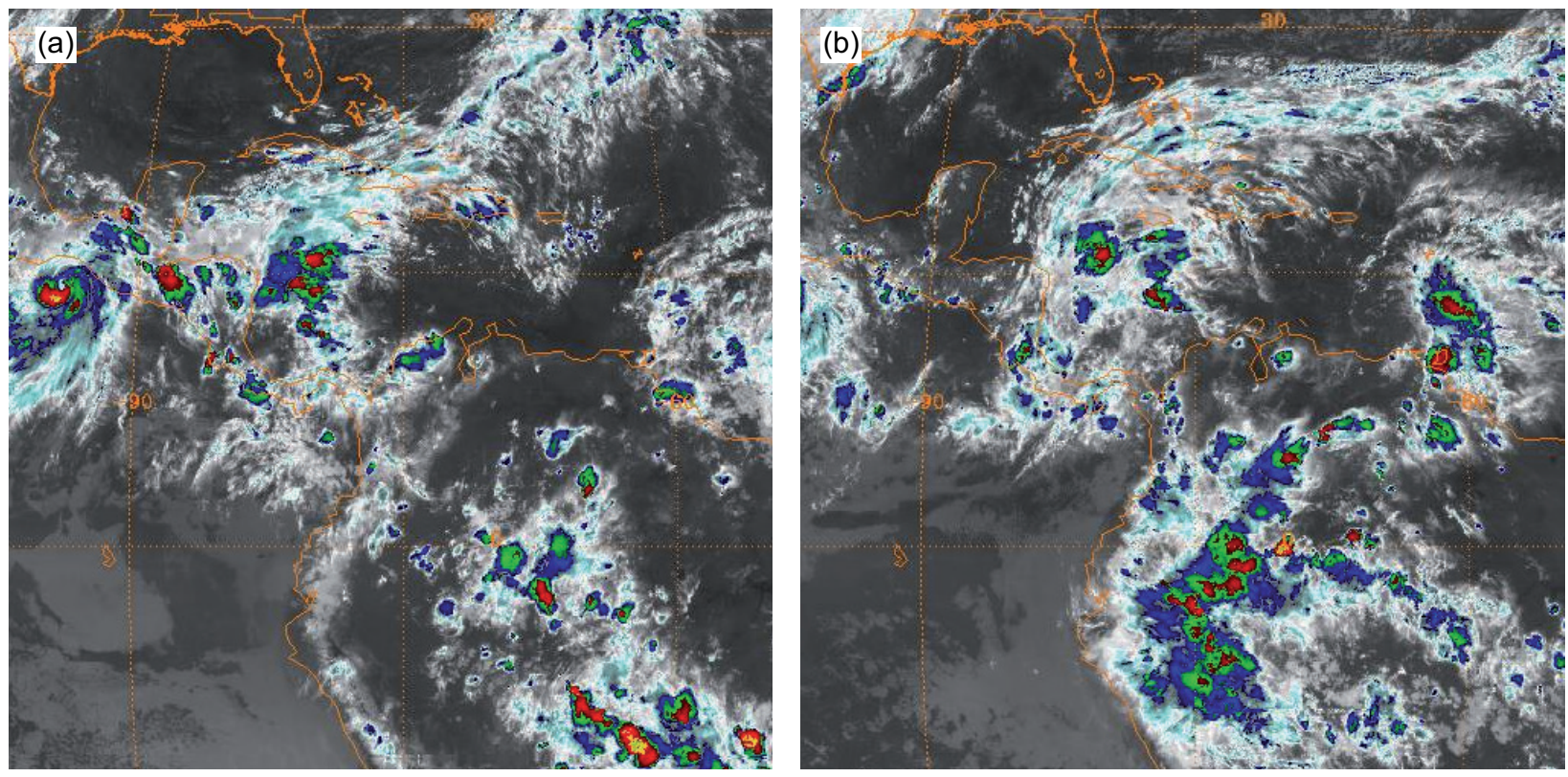

Fig. 2. GOES8-IR satellite images for (a) October 17, 1998 at 00:00 UTC and (b) October 18, 1998 at 23:45 UTC.

We must go back days before the tropical wave approached Jamaica, to understand the characteristics of the phenomenon that occured. By October 15at 00 UTC, at an average of 200-300 $\mathrm{hPa}$, two more trough lines originated: the first, oriented N-S, was located to the east side of HLA and the second (NE-SE) to the east side of the HLC. As the NW-SE trough to the NE of the HLC was longer, it quickly became a 
small A1 anticyclone on October 15 at 06 UTC. By October 16, the upper trough on the east side of the HLA was transformed into a small $\mathrm{C} 1$ cyclone at high levels and the A1 was amplified to the northeast of the HLC, allowing a SW-NE flow between $\mathrm{C} 1$ and A1, as shown in Figure 1a.

By October 17 at 00 UTC, a new tropical upper troposphere trough (TUTT) line oriented SW-NE was generated on the east side of the HLA. After the TUTT was transformed into a C2 cyclone of high levels on day 18 at 00 UTC (not shown), it allowed the formation of a small A2 anticyclone of high levels between $\mathrm{C} 1$ and $\mathrm{C} 2$. The presence of the HLA and this $\mathrm{C} 2$ cyclone of high levels disturbed the tropical flow to the southeast, creating a small chain of disturbances or waveguide composed of small cyclones and anticyclones, decreasing in amplitude toward the southeast (Fig. 3a). It was then that the tropical flow was disturbed at lower levels (Fig. 3b).

Under this condition, there was a flow to the NE between these small cyclones and anticyclones and the cloud cluster appeared, as shown in Figure 2b. In this place the tropical wave gained amplitude, which originated the tropical cyclone Mitch (Fig. 3b). The amplitude of A2 increased at the expense of the loss of energy and decrease in amplitude of the HLA. Later on, the $\mathrm{C} 2$ cyclonic circulation moved between the HLA and the HLC, and around the HLA. Because C2 was much closer to the HLA, it was guided by the circulation of the HLA and on October 22 it was located over Mexico (Fig. 5a).

By October 21 at 00:00 UTC, this horizontal distribution of the streamlines showed a hyperbolic deformation field, which developed on the east side of the dipolar vortex between the island of Puerto Rico and Colombia. The kinematics or motion geometry within the upper troposphere dipolar vortex, the conditions for La Niña event and the beginning of the tropical Mitch perturbation were examined by the potential function $\chi$ for the divergent average wind in the 200-300 hPa and 925-1000 hPa layers. We will see how another mechanism can disturb a tropical wave.

The intense warming of the warm pool of the eastern Pacific, the warm pool of the Caribbean, the Sierra Madre Occidental and the deserts of Chihuahua and Sonora cause the air to rise, which in turn generates a low surface pressure (centered near the coast NW-SW of Mexico and Central America), named as the maritime-continental thermal low (Pérez-García et al., 2017). Therefore, large horizontal convergences are generated at lower levels between the eastern Pacific about $100^{\circ} \mathrm{W}$ and the eastern Caribbean about $70^{\circ} \mathrm{W}$.

Figure $3 \mathrm{c}$ shows the convergent/divergent average wind and its corresponding potential function in the $925-1000 \mathrm{hPa}$ layer and the average relative humidity (gray shades) in the $700-925 \mathrm{hPa}$ layer for October 18, at 00 UTC. A notable feature in this figure is the strong convergence and high relative humidity throughout Central America, Mexico and the northwest of South America, since the Caribbean Sea, the eastern Pacific and the Gulf of Mexico serve as sources of atmospheric humidity for rainfall in the Americas (Hales, 1974; Ting and Wang, 1997; Barlow et al., 1998; Klimczak, 2000; Wang, 2007). Near the northeastern equatorial Pacific, the trade winds southwest of Baja California become wet toward Mexico and Central America (Fig. 3b).

A wide area of convergence extends between Mexico, Central America and just north of South America, while around it we can find the four primary centers of action, namely the Northeastern Pacific Subtropical High (NPSH), the Southeastern Pacific Subtropical High (SPSH), the Azores High or North Atlantic Subtropical High (NASH), and the South Atlantic Subtropical High (SASH). Diverging winds generate each one of these centers of action and contribute to the converging winds over America in the tropical region, as can be seen in Figure 3c. A transient anticyclone, indicated by the letters "TA", is also part of the convergence zone in tropical America.

In October, when the NASH is weak and extends to the NE, the SST in the Caribbean and NE Pacific near Mexico and Central America are abnormally warm (Wang, 2007). The SST anomaly chart of October 20, 1998, shows negative values in most of the eastern-central Pacific domain $\left(30^{\circ} \mathrm{S}-30^{\circ} \mathrm{N}\right.$, $\left.180^{\circ}-115^{\circ} \mathrm{W}\right)$ and minimum values along the equator, as corresponding to La Niña phase (http:// www.ospo.noaa.gov/data/sst/anomaly/1998/anomnight.10.20.1998.gif).

In Figure 3d we also observe the trajectories (blue) of these primary centers of action during most of October 1998. NASH and SASH remain almost stationary. From October 16 to 20 the trajectory of a migratory anticyclone (traced in red) labeled as TA1 

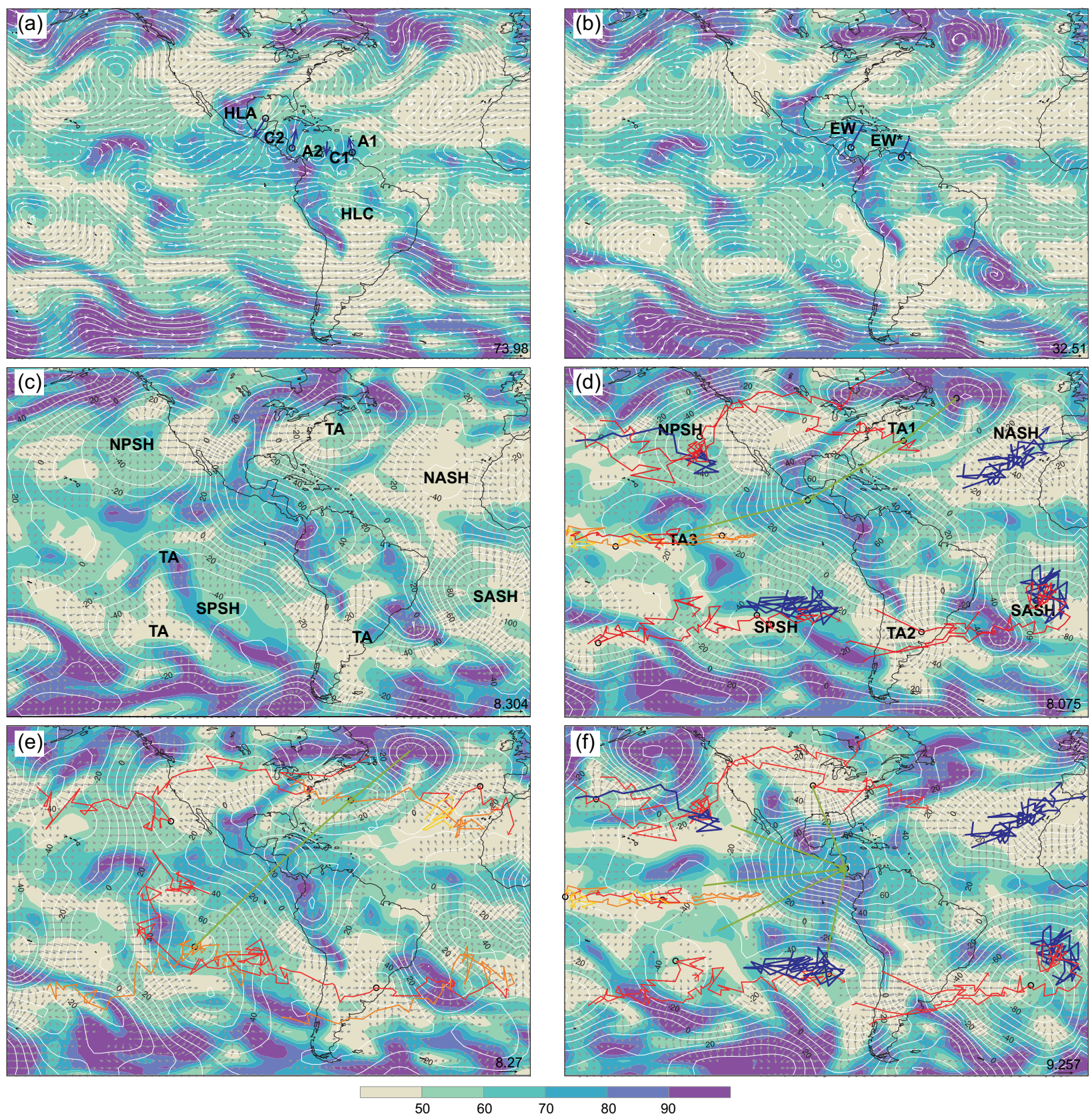

Fig. 3. (a) Same as in Fig. 1a, but for October 19, 1998 at 00 UTC. (b) Streamlines at $800 \mathrm{hPa}$ and mean relative humidity for the $700-925 \mathrm{hPa}$ layer for October 19, 1998 at $00 \mathrm{UTC}$. The axis of the eastern waves (EW and $\mathrm{EW}^{*}$ ) is marked by bars. Tropical cyclone Mitch originated from $\mathrm{EW}^{*}$ and $\mathrm{EW}$ is related to the cloud cluster located over the western Caribbean Sea. (c) Mean convergent/divergent wind and its corresponding potential function contours $\left(\times 10^{5}\right)$ in the 925-1000 hPa layer and mean relative humidity (shaded) in the 700-925 hPa layer for October 18, 1998, 00 UTC. (d) Same as in Fig. 3c, but for October 19, 1998, 00 UTC. Blue lines designate the trajectory of the primary centers of action and the red lines, transient anticyclones (in mid-latitudes), for the better part of October 1998; numbers indicate the initial and final day for each case. The transient connection pattern to La Niña is traced in green. (e) Same as Figure $3 \mathrm{c}$ for layer 200-300 $\mathrm{hPa}$. The trajectories in red and orange designate the greatest horizontal convergences for some transient anticyclones, during October 1998. The transient connection pattern to SPSH is traced in green for October 19, 1998, 00 UTC. (f) Same as in Fig. 3d, the connection pattern to SPSH and the transient connection pattern to the east of USA are traced with green for October 23, 1998, 00 UTC. 
can be observed, reaching northwest of the Atlantic Ocean by October 20. On October 23, the SPSH fluctuated zonally and suffered a TA2 dispersion that moved on October 24 over the southern part of South America. A third transient anticyclone TA3 was located near the equator of the central Pacific.

In Figure 3d, we track these transient anticyclones (red) from October 16 to 20 for TA1, from 18 to 21 for TA2 and from 17 to 19 for TA3 (not shown). We point out (orange) the centers of the dry air intrusion, with a W-E elongation generated near the equatorial central Pacific that which could be more related to a local air-ocean heat exchange process (La Niña phase) (Lindzen and Nigam, 1987) in the east-center of the cold water pool of the Pacific. This SST anomaly in the central-eastern Pacific seems to explain the dry air intrusion and the zone of divergence.

In the 925-1000 $\mathrm{hPa}$ mean layer of the lower troposphere (Fig. 3d), we find the convergence on tropical America that connects (represented by a green line) with two other divergent centers of TA3 (or SPSH) and TA1 action; moreover, TA1 may have been connected to the northeast with a convergent center. TA1, TA3, NASH, SPSH and the wide area in the eastern central Pacific (the area of $30^{\circ} \mathrm{S}-30^{\circ} \mathrm{N}$ and $160^{\circ}-120^{\circ} \mathrm{W}$ ) had a direct influence on the low level convergence in the tropical region of America.

The greatest horizontal divergences were generated in the middle and upper levels of the troposphere (Fig. 3e) and the convergences were generated in the lower levels (Fig. 3c and 3d), favoring the different stages of development of the tropical system in the Caribbean Sea, as shown above with more details. The warm air rises and cools in a low pressure zone and the areas of descending air produce high pressure zones. In the region between the southeastern Pacific and Central America, convergent-divergent cells are formed at low to high levels. The zone of convergence located between Mexico and the North Atlantic, seen in Figure 3d, is associated with the position of the migratory anticyclone TA1.

The connection between TA1 and TA 3 is called Transient Connection Pattern to La Niña (TCPNa). It describes the convection cells of northeastern and southeastern Central America. TA1 is connected to the northeast with a convergent center located in the North Atlantic. However, this convergent field can also be connected to a divergent field located in
Greenland as shown in Figure 3d. TCPNa is an alternate pattern between pressures in the central Pacific Ocean and various centers of action in Central America and the northwest Atlantic Ocean. Another route for this connection is through the divergent eastern Pacific centers of action and with North America as in the Pacific/North American (PNA) Classic Pattern (Barnston and Livezey, 1987).

The four primary centers of action and the transient anticyclone are associated with the convergent/ divergent fields in the 200-300 hPa layers as seen in Figure 3e. An intensified elongation of the NW-SE direction in the divergence field appears over Central America and a divergence is also observed with a more marked asymmetry over the north Atlantic. A stronger and more southern convergence was limited to the southeast Pacific, while a weaker convergence was observed over the northwest north Atlantic, thus creating a NW-SE feedback system. The wide field of divergence that appears over Mexico, Central America and the northwest of the Southern Hemisphere unites them from above.

On the SPSH center of action on October 19, 1998, in the upper average atmosphere of $200-300 \mathrm{hPa}$, there is a strong convergence that connects the three different convergent, divergent and convergent centers of action, as shown in Figure 3e, which we call the connection pattern to SPSH. According to the classification of teleconnection weather patterns by Barnston and Livezey (1987), two of these patterns are the North Atlantic Oscillation (NAO) and the PNA. The NAO is a north-south oscillation on the path of storms and depressions across the north Atlantic and flows into Europe. It has been observed that the positive phase of the PNA is strongly related to the ENSO phenomenon, while the negative phase tends to be associated with $\mathrm{La}$ Niña. In this work, the SPSH and TCPNa connections are not statistical patterns of low frequency variability, because their occurrence lasts only a few hours or a few days at most.

Figure 4 shows schematically the relative humidity in the 700-925 hPa layer and the average field of streamlines for the upper layer $(200-300 \mathrm{hPa})$ from October 17 to November 4 . The most interesting feature of this mean field of streamlines that passes over the tropical America region is a dipolar vortex formed by the HLC and the HLA. This dipolar vortex, which has a Gill-Matsuno wave configuration (Pérez-García 


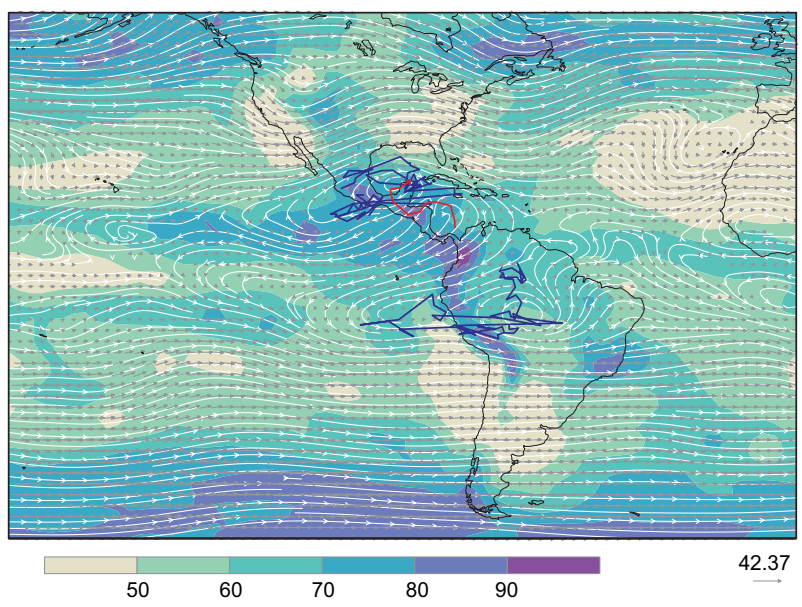

Fig. 4. Mean streamlines at 200-300 hPa, mean RH at 700 $925 \mathrm{hPa}$ and trajectories (blue lines) of the HLC and HLA vortices from October 17 to November 4, 1998. The red line represents Hurricane Mitch trajectory from October 22 to November 4, 1998.

et al., 2017), is the main research topic in this work. This may have contributed to the movement of tropical cyclone Mitch to the SW, as shown below. Figure 4 also shows the trajectories of the HLC, HLA and Mitch vortices, respectively, and it is observed how this tropical cyclone moved between the HLC and the HLA.

When comparing Figures $3 \mathrm{c}$ and 4 , we noticed that the dipolar vortex and the tropical wave that would give rise to tropical cyclone Mitch were trapped within a convergence zone below (Fig. 3c) and a divergence zone above. To understand a tropical dipole circulation formed by an anticyclone at the upper level, it is necessary first to understand how an HLA is formed, where rainfall occurs and how it relates to the development of tropical cyclones within that dynamic system.

Following the streamlines analysis maps in Figure 4, we can see the movement of tropical cyclone Mitch within a dipolar vortex as a dynamic system. We examine below the resulting stationary perturbation in the linear barotropic model, using a numerical spectral method (Skiba and Pérez-García, 2009) that is tested for an isolated stationary equatorial modon similar to that constructed by Verkley (1984). As the northeast wind flowed to the eastern Pacific (October 2100 UTC, 200-300 hPa layer), a longitudinal band of strong northeasterly winds (located between the HLC and the HLA in the eastern Pacific) intensified, forming a difluent jet (between Panama and Nicaragua) that can form a line of divergence and induce a convergence zone on the surface, which is why a convergence nucleus was observed at the 925-1000 $\mathrm{hPa}$ level in the southwest region of the Caribbean Sea. Therefore, frontogenesis (Keyser et al., 1988; Pérez-García, 1993) was driven by the confluence to form a higher level front and two jet cores oriented SW-NE and directed to opposite sides. The southeastern core might have intensified the disturbance at the lower levels or to the tropical wave.

A new TUTT oriented SW-NE was developed towards the east side of the HLA, then it was transformed into an upper-level low C2 on October 21 at 18 UTC (not shown). This allowed the formation of an upper-level high A2 east of the C2, thus the condition of October 19 (Fig. 3a) was replicated on October 22 at 18 UTC (Fig. 5a). A jet core located between HLA and the C2 oriented NE-SW and directed towards the western Caribbean Sea makes the low level tropical disturbance unstable, which would give origin to Mitch (Fig. 5c).

The TUTT and the upper-level low $\mathrm{C} 2$ appeared when the HLA was of greater amplitude and with an almost symmetric circulation. In addition, the HLC was more elongated towards the west. Thus, as a result of the external mechanisms of tropical cyclone formation (Montgomery and Farrell, 1993), the tropical depression that gave rise to Mitch was formed below the line of divergence between the HLC and the $\mathrm{C} 2$ on October 22 at $18 \mathrm{UTC}$, about $76^{\circ} \mathrm{W}$, $12^{\circ} \mathrm{N}$. A line of divergence in the upper troposphere (Fig. 5a) induces a zone of convergence at lower levels (Fig. 5b), and may become a mechanism giving rise to tropical disturbances (see Fig. $5 \mathrm{c}$ and Pérez-García et al., 2016). This area of convergence is reinforced by the connections established SW of the eastern Pacific and to the east of the United States (Fig. 5b).

Early on October 24, Mitch became a hurricane. Later that day, as it moved westward, it began to intensify rapidly. In about 24 hours, its central pressure dropped to $924 \mathrm{hPa}$ on the afternoon of October 25 . The center of the high divergence zone associated with the dipolar vortex $(200-300 \mathrm{hPa})$ was located on the southwest of the Caribbean Sea on October 25 (not shown). Mitch continued to strengthen and its central pressure reached a minimum of $905 \mathrm{hPa}$ some 

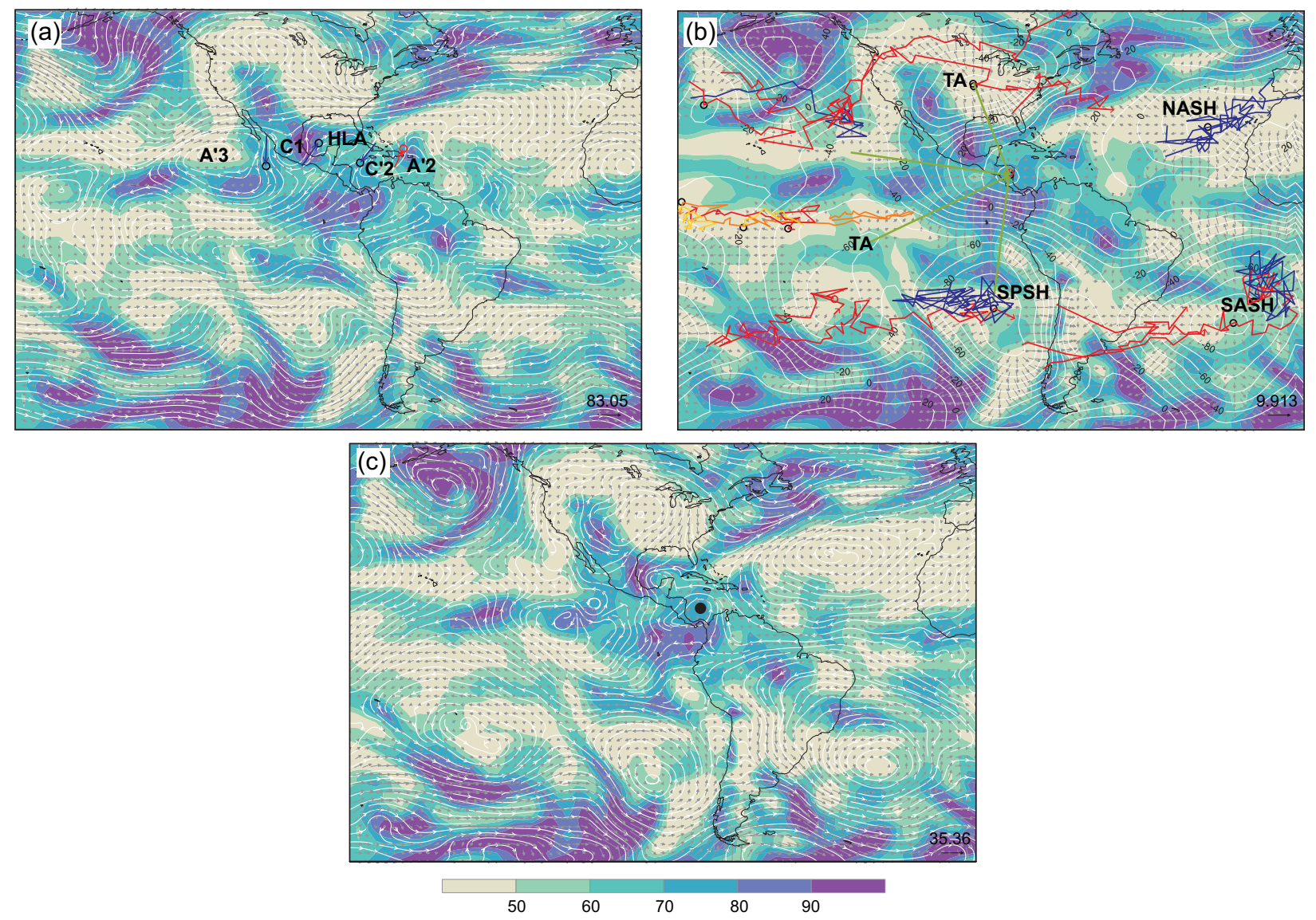

Fig. 5. (a) Same as in Fig. 3a, but for October 22, 1998 at 18 UTC. The successive disturbances are anticyclones A3, HLA, small cyclones C1 and C2 and anticyclone A2. (b) Same as in Fig. 3b, but for October 22, 1998 at 18 UTC. The connection patterns to the convergence zone of Central America are traced in green. (c) Streamlines at $800 \mathrm{hPa}$ and mean relative humidity in the 700-925 hPa layer for October 22, 1998 at 18 UTC. Mitch is identified by a dot.

40 miles southeast of Swan Island on the afternoon of October 26 (Guiney and Lawrence, 1999; PérezGarcía et al., 2017).

\section{Gill-Matsuno waves or modons in the tropical region}

There have been many theoretical studies on tropical waves. Matsuno (1966) showed that there are several types of wave patterns in the tropical region: equatorial Kelvin waves, equatorial Rossby waves and inertial-gravity waves. Equatorial waves are an important class of perturbations in the tropical atmosphere that are trapped near the equator and propagate eastward and westward. Equatorial Rossby waves are characterized by a pair of cyclonic/anticyclonic circulation anomalies, and are equatorially symmetric. Gill
(1980) discussed the response of tropical circulation to prescribed heat sources by solving a very simple linear shallow water model. The Gill model is remarkably successful in reproducing the main features of a tropical flow or monsoon circulation. However, the tropical circulation driven by convective heating is a highly non-linear system.

Yet, we do not have a clear idea of the structure of a dipolar vortex and how it advances or goes back over the eastern Pacific or the Caribbean Sea during the pre or post summer monsoon season, or how the mountainous systems of northern South America, Central America and Mexico affect the wind circulation.

We previously discussed the evolution of a tropical wave associated with the genesis of Mitch, and how it was related to the HLA and the HLC vortices 
(Figs. 3a, b and 5a, c). In the mean field of the upper layer (200-300 hPa) from October 17 to November 4 we observed a dipolar vortex with an NW-SE orientation. In general, the HLC oscillates zonally and the HLA oscillates towards the SW-NE. The main characteristic in this case is that the HLA was generally found in Mexico, while the HLC was above South America. Hence, a very simple idealization of the structure of a north-south dipolar vortex would be the modon solution (Verkley, 1984) trapped near the equator, which is qualitatively similar to the dipole blocking pattern observed in the midlatitude atmosphere (Frederiksen, 1982). Tribbia (1984), Verkley (1984, 1987, 1990) and Neven (1992) constructed exact, highly nonlinear solutions of the BVE on the rotating unit sphere called modons. It is well known that there are wave-like modons, localized modons, and uniform modons that can arise as a result of local forcing (Neven, 2001). Then we can consider the vertical component of the vorticity equation, which can be written in the non-dimensional form as:

$\frac{\partial \Delta \Psi}{\partial t}+J(\Psi, \Delta \Psi+2 \mu)=0$

where $\Psi(\lambda, \mu)$ denotes the stream function, $\mu=\sin$ $\phi=\cos \theta,-\pi \leq \lambda \leq \pi,-\frac{\mu}{2} \leq \phi \leq \frac{\mu}{2}, 0<\theta<\pi, \lambda$ the longitude, $\phi$ the latitude and $\theta$ the colatitude. $\Delta$ is the Laplace operator on a sphere, $J(\Psi, \varsigma)$ is the jacobian and $\varsigma=\Delta \Psi+2 \mu$ is the absolute vorticity. Despite the simplicity of the BVE, it contains the main elements which describe the complexity of the atmospheric behavior (Simmons et al., 1983). Exact solutions for Eq. (1), called Rossby-Haurwitz waves and modons are of metereological interest and may provide information on the tropical circulation (Pérez-García, 2014).

In this paper, Verkley's (1984) localized modon is considered appropriate to describe some types of dipolar wave patterns in the tropical region that are stable in small-scale perturbations (Pérez-García and Skiba, 1999). The modon solution can be constructed by dividing the sphere $S$ into two regions: an inner region $S_{i}$ centered around the pole $N$ ' and an outer region $S_{o}$ separated from the inner region by a boundary circle $\partial S_{i}$ over which $\Psi$, $\varsigma$ and its normal derivative are continuous. Let us now decompose the stream function into an eigenfunction part $\Psi_{1}\left(\lambda^{\prime}\right.$, $\left.\mu^{\prime}\right)=Y_{v}\left(\lambda^{\prime}, \mu^{\prime}\right)$ and a zonal part $\Psi_{2}(\lambda, \mu)=-\omega \mu+d$, where $-\omega \mu$ is a solid body rotation and $d$ is constant (Pérez-García, 2015). The following is a solution for Eq. (1) on the sphere as proposed by Verkley (1984, 1987, 1990) and Neven (1992):

$$
\begin{aligned}
\Psi(\lambda, \mu)=\Psi_{1}\left(\lambda^{\prime}, \mu^{\prime}\right)+\Psi_{2}(\lambda, \mu)= \\
\qquad \begin{array}{l}
X_{i}\left(\lambda^{\prime}, \mu^{\prime}\right)-\omega_{i} \mu+d_{i}, \text { in } S_{i} \\
X_{o}\left(\lambda^{\prime}, \mu^{\prime}\right)-\omega_{o} \mu+d_{o}, \text { in } S_{o}
\end{array}
\end{aligned}
$$

where $\left(\lambda^{\prime}, \mu^{\prime}\right)$ are the spherical coordinates relative to a rotated pole $N$ ' with coordinates $\left(\lambda_{0}, \mu_{0}\right)$ with respect to the original system, and both $X_{i}$ and $X_{o}$ are eigenfunctions of the Laplace operator $-\Delta$ on $S$ corresponding to the eigenvalue $\chi_{\alpha}=\sigma(\sigma+1)$ and $\chi_{\sigma}$ $=\sigma(\sigma+1)$. Then Eq. (2) describes a configuration in which the structure $Y_{v}$ moves through the zonal flow $-\omega \mu$ with constant velocity $c_{v}$ and without changing the size or shape. The pole of the primed system $N^{\prime}$ that moves along a latitude at a constant angular velocity $c_{v}$ is given by

$c_{v}=\omega_{v}-\frac{2\left(\omega_{v}+1\right)}{\chi_{v}}$

where $\chi_{v}$ is an eigenvalue of the spectral problem $\Delta Y_{v}=-\chi_{v} Y_{v}$. As $c_{\alpha}=c_{\sigma}$ then $\left(2-\chi_{\alpha}\right) \omega_{\alpha}=\left(2-\chi_{\sigma}\right) \omega_{\sigma}$ $=-2$ for a stationary Verkley (1984) modon, where $\sigma=-\frac{1}{2}+i k$, with $i$ being the imaginary unit, $\chi_{\sigma}=\sigma(\sigma$ $+1)=-\left(k^{2}+0.25\right)<0$ and $\chi_{\sigma}=\alpha(\alpha+1)>0$.

In the primed coordinates, the isolated and stationary model of Verkley (1984), whose structure is described by Eq. (2), are

$$
X_{i}\left(\lambda^{\prime}, \mu^{\prime}\right)=A_{i} P_{\alpha}^{1}\left(\mu^{\prime}\right) \cos \lambda^{\prime}+B_{i} P_{\alpha}^{0}\left(\mu^{\prime}\right)
$$

and

$$
X_{o}\left(\lambda^{\prime}, \mu^{\prime}\right)=A_{o} P_{-0.5+i k}^{1}\left(\mu^{\prime}\right) \cos \lambda^{\prime}+B_{o} P_{-0.5+i k}^{0}\left(\mu^{\prime}\right)
$$

Using a grid of $5 \times 5^{\circ}$ on the local coordinate associated with the chart ( $\left.\lambda^{\prime}, \mu^{\prime}\right)$, the Verkley (1984) modon was generated numerically (Pérez-García and Skiba, 1999; Pérez-García, 2015). This modon solution was built with the following parameters: $k=$ $10, \alpha=10, \alpha_{a}=\sin \left(66.14^{\circ}\right), \mu_{0}=\sin \left(10^{\circ}\right), \lambda_{0}=270^{\circ}$ and $d_{0}=0$. As the function $f\left(\lambda^{\prime}\right)=\cos \lambda^{\prime}$ has the period $2 \pi$, therefore $f\left(a \lambda^{\prime}\right)$ will have the period $\frac{2 \pi}{|a|}$ where $a$ is a real number other than zero. At a $35^{\circ}$ angle from the N-S direction, we reoriented the modon to an 
NW-SE direction, thus $a=\frac{72}{79}$. The NW-SE tropical modon seen in the group of geographic coordinates $(\lambda, \mu)$ is shown in Figure 6a and has been constructed in such a way that it is stationary.

Eq. (1) was integrated numerically over time in the non-linear form using the spectral transform technique, as in Pérez-García and Skiba (1999) and Pérez-García et al. (2017). The basic flows used in this study are shown in Figure 6a. As the numerical simulation evolves slowly, the tropical modon moves towards the southwest. The rotational winds of the tropical model, combined with the north-south variation of the Coriolis parameter, induce asymmetries of relative vorticity in the dipolar circulation that are called beta-gyres (Holland, 1983).

An NW-SE oriented tropical upper tropospheric trough was generated towards the east side of the HLC. As a coupled system, the HLA and HLC rotate in a clockwise direction after $24 \mathrm{~h}$ of integrating the model (see Fig. 6b). Sadler (1976) noted that in the summer the TUTT is a dominant feature over the trade winds regions of the Gulf of Mexico and the Caribbean Sea.

In order to examine the interaction process between HLA, HLC and Mitch, in Pérez-García et al. (2017) the non-linear BVE was integrated in time applied to the $800-200 \mathrm{hPa}$ average layer, at the moment prior to Mitch's movement towards the SW. During this period, from October 26 to 28, the HLA and the HLC as a coupled system rotated clockwise as observed (Pérez-García et al., 2017).

Near the equator, the planetary vorticity is approximately zero and the relative vorticity is smaller due to weak wind shear. However, within a tropical modon configuration there is sufficient horizontal wind shear, mainly along the central zonal flow. The instability caused by the existence of a sufficiently large horizontal shear of the basic flow is known as barotropic instability (Pedlosky, 1979). The disturbance theory is based on the mechanisms of baroclinic and barotropic instability and has been associated to the appearance and decay of largescale waves and vortices (Neven, 1992). Simmons et al. (1983) showed that barotropic instability may be responsible for the low frequency variability of the barotropic atmosphere. To examine the resulting stationary perturbation in the linear barotropic model, Skiba and Pérez-García (2009) developed a numerical spectral method for studying the normal mode stability of ideal flows in a rotating sphere, which was tested for an isolated stationary equatorial modon built by Verkley (1984). The solution to this more generalized linearized problem about the stationary basic flow $\Psi$ is:
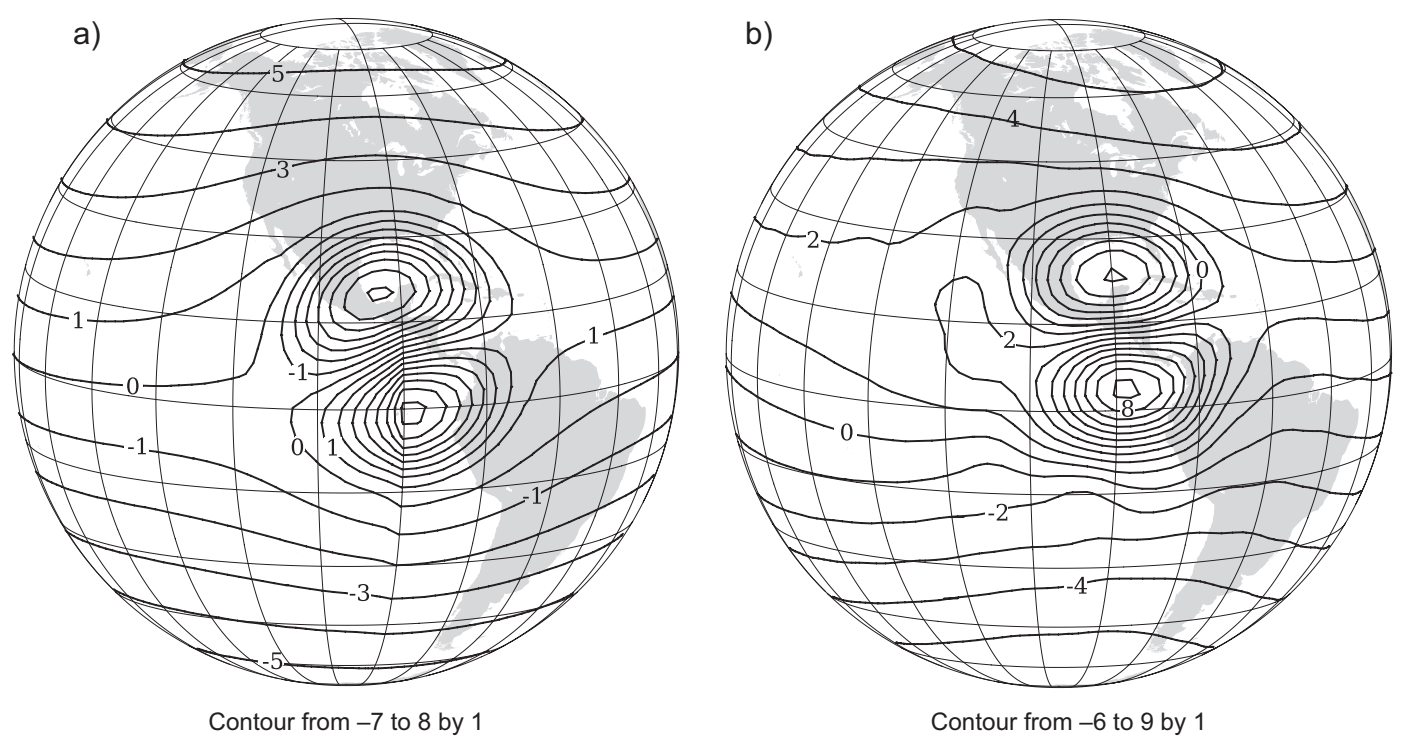

Fig. 6. Isolines of (a) the stream function of a tropical modon (Verkley, 1984) with a NW-SE orientation and (b) after 24 hours of integrating the T31 model. The contour values are multiplied by $10^{7}$. 
Table I. The most unstable mode of the tropical modon described in Eq. (5).

\begin{tabular}{lcrrcc}
\hline Modes & $\omega_{r}$ & $\omega_{i}$ & $\chi \hat{\Psi}$ & $\tau_{e}$ (days) & $T$ Period (days) \\
\hline 1 & 0.42059 & 0.6969 & 126.9093 & 0.3784 & 1.4347 \\
2 & 0.10886 & 0.4686 & 178.1732 & 1.4619 & 2.1335 \\
3 & 0.09325 & -1.2545 & 259.7882 & 1.7066 & 0.7971 \\
\hline
\end{tabular}

$\frac{\partial \varsigma^{\prime}}{\partial t}+\mathcal{L} \varsigma^{\prime}=\sigma \xi^{\prime}=v(-\Delta)^{s+1} \psi{ }^{\prime}$

where $\varsigma^{\prime}=\xi^{\prime}+2 \mu$ and $\xi^{\prime}=\Delta \psi$ ' are the absolute and relative vorticities of the disturbance, respectively:

$$
\begin{gathered}
\mathcal{L} \varsigma^{\prime}=J\left(\tilde{\varphi}, \varsigma^{\prime}\right)+J\left(\Delta^{-1} \xi^{\prime}, \tilde{\varsigma}\right) \\
\psi^{\prime}(\lambda, \mu, t)=\hat{\Psi}(\lambda, \mu) e^{\omega t}, \\
\xi^{\prime}(\lambda, \mu, t)=\Delta \hat{\Psi}(\lambda, \mu) e^{\omega \mathrm{t}}=G(\lambda, \mu) e^{\omega \mathrm{t}}
\end{gathered}
$$

Which leads to the spectral problem

$$
\mathbf{L} G=\omega G,
$$

for the linearized operator $\mathbf{L} G=J\left(\tilde{G}, \Delta^{-1} G\right)-J(\hat{\Psi}, G)$ $-\left[\sigma+v(-\Delta)^{S}\right] G$, where $\omega=\omega_{r}+i \omega_{i}$ is the eigenvalue and $G$ the eigenfunction. Eq. (5) is solved with $\sigma=v=$ 0 , representing all the variables as series of spherical harmonics and using the triangular truncation T31. A mode $\psi^{\prime}$ is unstable if $\omega_{r}>0$, in decay if $\omega_{r}<0$, neutral if $\omega_{r}=0$, and stationary if $\omega_{i}=0$.

The main parameters of the first three most unstable modes are shown in Table I. The e-folding time $\tau_{e}=\frac{1}{2 \pi \mid \omega_{r}}$, the period $T=\frac{1}{\left|\omega_{i}\right|}$ and the spectral number $\chi_{\hat{\psi}}=\frac{\eta \hat{\psi}}{K \hat{\psi}}$, where $\eta \hat{\psi}$ and $K_{\hat{\psi}}$ are the enstrophy and the mode amplitude energy. Therefore, unlike the zonal flows and the Rossby-Haurwitz waves, the instability condition for a normal mode of the tropical model depends not only on the degree of solution but also on the spectral distribution of the energy mode in the internal and external regions of the solution (Skiba and PérezGarcía, 2009).

The basic flow profile is shown in Figure 6a and the isolines of the amplitude $\operatorname{Re} \hat{\Psi}=\Psi_{r}(\lambda, \mu)$ of the first three most unstable modes are presented in Figure 7. Disturbances emanate around the modon.

For the first most unstable mode (Fig. 7a), the dipolar vortex has two major perturbations, one generated over the region of the incoming flow and the other over the region of the outgoing flow over the internal zonal part of the dipolar vortex. It has a larger amplitude on its southwest edge with values $\Psi_{r}<0$ and on its northeast edge with values $\Psi_{r}>0$. A zonally elongated disturbance (induced secondary circulation) is located on its northern edge with values $\Psi_{r}<0$ and a disturbance with values $\Psi_{r}>0$ on the NW side of the dipolar vortex.

For the second most unstable mode (Fig. 7b), a disturbance is generated on the dipolar vortex that stretches meridionally with values $\Psi_{r}<0$. The disturbances of the north or northeast with $\Psi_{r}<0$ and on the east with $\Psi_{r}>0$ of the dipolar vortex make a chain similar to what occurs in the observations.

The third most unstable normal mode has a complex structure, as seen in Figure 7c, and perturbations are generated around each HLA vortex and HLC of the tropical modon. For tropical cyclones such as Mitch, the $\beta$-drift is generally northwestward at a few knots and depends on the location of the cyclone within the dipolar vortex. As the flow evolves, the $\beta$-turns are further away from the center of the storm and rotated cyclonically by the storm's rotational winds (Holland, 1983; Chan and Williams, 1987). However, tropical cyclone Mitch moved around the HLA from October 28 to November 4.

\section{Conclusions}

In this work we analyzed the movement of tropical cyclone Mitch (1998) with different approaches, such as observations, nonlinear dynamics and the linear barotropic instability of the BVE. We also examined the patterns that led to the development and trajectory of Mitch.

In the genesis of this cyclone, there were interesting mechanisms associated with the intensification of the tropical wave. Giving way to a small chain of disturbances that formed and extended to the southeast, composed of the HLA, smaller-scale cyclones C' and small-scale anticyclones A'. The A' was formed within the TUTT, on the northeast side of the HLC 

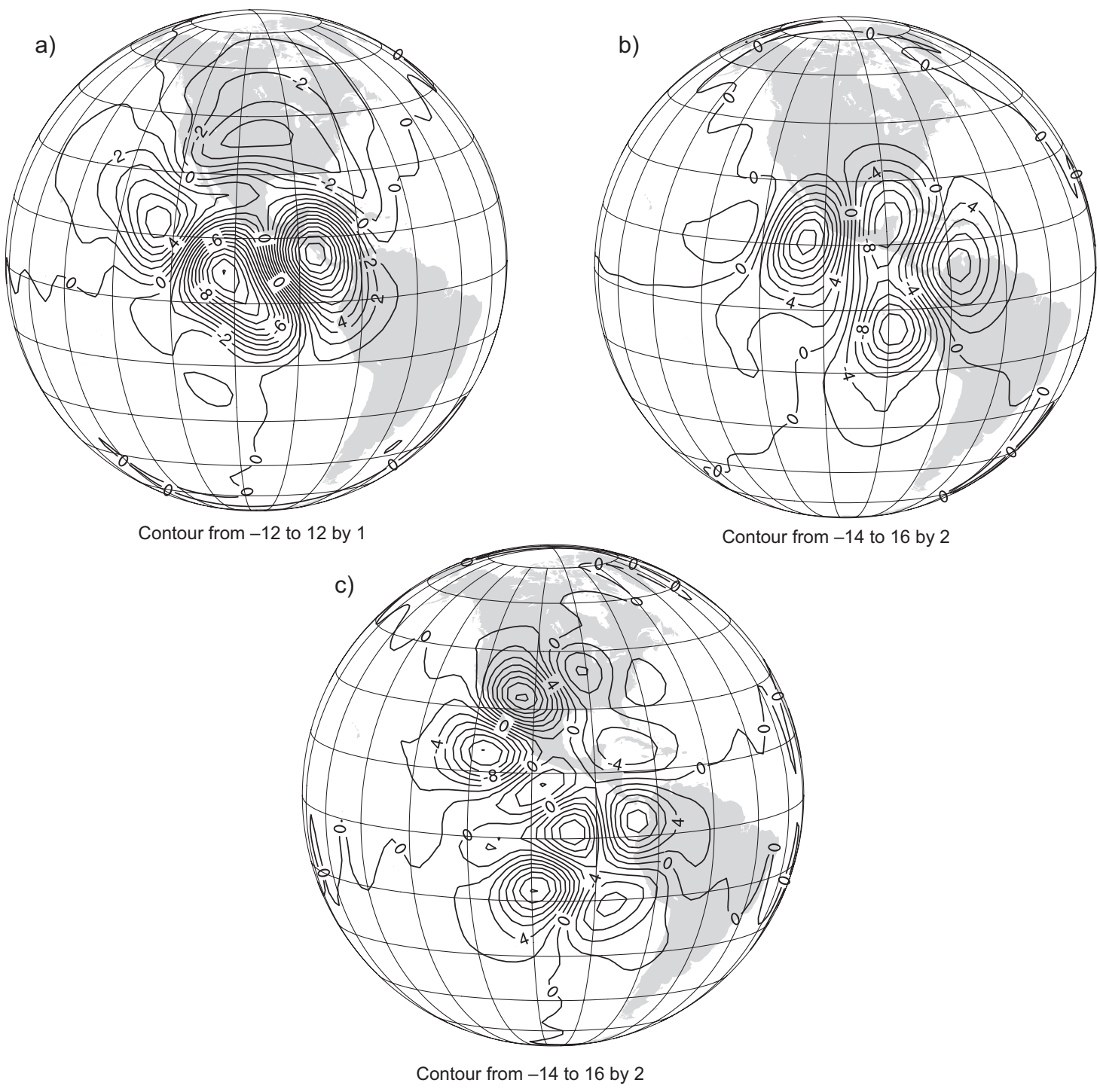

Fig. 7. Isolines of the real part of the amplitude for the first three most unstable normal modes.

and moved northwest towards the nearby Caribbean Sea as the HLC was further to the east. The anticyclones A' may also have been formed by cutting the subequatorial crest of the western branch. We established the main characteristic of the way in which the chain of disturbances can affect the easterlies, tropical waves or tropical depressions.

The convergence zone located on Mexico, the Caribbean Sea and Central America that contributed to the genesis of tropical cyclone Mitch, was reinforced by the strong link established to the SW on the eastern Pacific called TCPNa or the connection pattern to the subtropical high of the southeast Pacific. This link describes the convection cells of southwestern and northeastern Central America. Convection cells in northeastern Central America, which may exist largely through the northwestern Atlantic or eastern USA, called migratory anticyclone connections, also had direct influence on low-level convergence in the tropical region of America.

The most notable feature from October 17 to November 4 in the in the upper tropospheric mean circulation over the tropical region of America, was a dipolar vortex oriented NW-SE associated with the anticyclonic system of North America at the end of the summer and the anticyclonic system of South 
America during the early warm season with the HLA anticyclone in the northwest and an HLC anticyclone in the southwest. The purpose of this paper is to understand how the HLA and the HLC interacted during this period and how they may have contributed to the movement of tropical cyclone Mitch.

The simplest idealization of the NW-SE dipolar vortex is a modon (Verkley, 1984), which is an exact solution of the BVE on a rotating sphere. According to the observations, a NW-SE dipolar circulation pattern was constructed in such a way that it remained stationary and only needs to be adjusted to the data, which is the subject of future works.

This was considered as the basic flow for the study of the non-linear evolution and the linear barotropic instability of the BVE. Therefore, for the non-linear solution, the incursions of upper tropospheric troughs in the tropics influenced the resulting tropical disturbance. In order to examine the results of perturbations in the linear barotropic model, a numerical spectral method was applied for the stability study in normal mode for the NW-SE dipolar pattern. The perturbations that emanated around the modon and those of greater amplitude were generated along the difluent flow and confluent flow of the tropical modon. For the second most unstable normal mode, the perturbations located northeast side of the tropical modon were similar to the observations.

\section{Acknowledgments}

We would like to thank D. Adams for his comments on the first version of the manuscript. The authors are also grateful to E. Azpra, F. J. Villicaña, A. Salas and R. Meza for their technical assistance with the maps analysis and to N. Aguilar, A. Alazraki, A. González and C. Márquez for their help to improve the manuscript. The data were provided by NCAR's Data Support Section (DSS), the NSF is NCAR's sponsor. The satellite images were obtained from https:/www.ncde.noaa.gov/gibbs/.

\section{References}

Amador J.A., E.J. Alfaro J., Lizano O.G. and Magaña V.O., 2006. Atmospheric forcing of the eastern tropical Pacific: A review. Prog. Oceanogr. 69, 101-142.

DOI: $10.1016 /$ j.pocean.2006.03.007
Avila L.A. and Pasch R.J., 1995. Atlantic tropical systems of 1993. Mon. Weather Rev. 123, 887-896.

Barlow M., Nigam S. and Berbery E.H., 1998. Evolution of the NorthAmerican monsoon system. J.Climate 11, 22382257. DOI: $10.1175 / 1520-0442(1998) 011<2238$ :EOTNAM $>2.0 . \mathrm{CO} ; 2$

Barnston A.G. and Livezey R.E., 1987. Classification, seasonality and persistence of low- frequency atmospheric circulation patterns. Mon. Weather Rev. 115, 1083-1126. DOI: 10.1175/1520-0493(1987)115<1083: CSAPOL $>2.0 . \mathrm{CO} ; 2$

Burpee R.W., 1972. The origin and structure of easterly waves in the lower troposphere of North Africa. J. Atmos. Sci. 29, 77-90. DOI: 10.1175/1520-0469 (1972)029<0077:TOASOE >2.0.CO;2

Camargo S.J., Emanuel K.A. and Sobel A.H., 2007. Use of a genesis potential index to diagnose ENSO effects on tropical cyclone genesis. J. Climate 20, 4819-4834. DOI: $10.1175 /$ JCLI4282.1

Chan J.C.L. and Williams R.T., 1987. Analytical and numerical studies of the beta-effect in tropical cyclone motion. Part I: Zero mean flow. J. Atmos. Sci. 115, 1238-1252. DOI: $10.1175 / 1520-0469(1987) 044<1257$ :AAN$\mathrm{SOT}>2.0 . \mathrm{CO} ; 2$

Demaria M. and Kaplan J., 1994. Sea surface temperature and the maximum intensity of Atlantic tropical cyclones. J. Climate 7, 1324-1334.

DOI: 10.1175/1520-0442(1994)007<1324:SSTAT$\mathrm{M}>2.0 . \mathrm{CO} ; 2$

ECMWF 2009, updated monthly. ERA-Interim Project. European Centre for Medium-Range Weather Forecasts. Available at: https://www.ecmwf.int/en/ forecasts/datasets/archive-datasets/reanalysis-datasets/ era-interim (last accessed on November 30, 2016).

Frank N., 1968. The "Inverted V" cloud pattern-an easterly wave? Mon. Weather Rev. 97, 130-140.

DOI: 10.1175/1520-0493(1969)097<0130: TVCPEW $>2.3 . \mathrm{CO} ; 2$

Frederiksen J.S., 1982. A unified three-dimensional instability theory of the onset of blocking and cyclogenesis. J. Atmos. Sci. 39, 969-982.

Gill A.E., 1980. Some simple solutions for heat induced tropical motion. Quart. J. Roy. Met. Soc. 449, 447-462. DOI: 10.1002/qj.49710644905

Goldenberg S.B., Landsea C.W., Mestas-Núñez A.M. and Gray W.M., 2001. The recent increase in Atlantic hurricane activity: Causes and implications. Science 293, 474-479. DOI: 10.1126/science. 1060040 
Gray W.M., 1984. Atlantic seasonal hurricane frequency. Part 1: El Nino and $30 \mathrm{mb}$ quasi-biennial oscilation influence. Mon. Weather Rev. 112, 1649-1668.

DOI: 10.1175/1520-0493(1984)112<1649:ASHF$\mathrm{PI}>2.0 . \mathrm{CO} ; 2$

Guiney J.L. and Lawrence M.B., 1999. Atlantic hurricane season. Preliminary report hurricane Mitch 22 October - 05 November 1998. NHC, NOAA. https:// www.nhc.noaa.gov/data/tcr/AL131998_Mitch.pdf

Hales J.E. Jr., 1974. Southwestern United States summer monsoon source. Gulf of Mexico or Pacific Ocean? J. Appl. Meteorol. 13, 331342.

DOI: $10.1175 / 1520-0450(1974) 013<0331$ : SUSSMS $>2.0 . \mathrm{CO} ; 2$

Hellin J. and Haigh M.J., 1999. Rainfall in Honduras during Hurricane Mitch. Weather 54, 350-359.

DOI: $10.1002 / j .1477-8696.1999 . t b 05534 . x$

Holland G.J., 1983. Tropical cyclone motion: Environmental interaction plus a beta effect. J. Atmos. Sci. 40, 328342. DOI: 10.1175/1520-0469(1983)040<0328:TCMEIP>2.0.CO;2

Inoue M., Handoh I.C. and Bigg G.R., 2002. Bimodal distribution of tropical cyclogenesis in the Caribbean: Characteristics and environmental factors. J. Climate 15, 2897-2905.

DOI: $10.1175 / 1520-0442(2002) 015<2897$ :BDOT$\mathrm{CI}>2.0 . \mathrm{CO} ; 2$

Kalnay E., Kanamitsu M., Kistler R., Collins W., Deaven D., Gandin L., Iredell M., Saha S., White G., Woollen J., Zhu Y., Chelliah M., Ebisuzaki W., Higgins W., Janowiak J., Mo K.C., Ropelewski C., Wang J., Leetmaa A., Reynolds R., Jenne R. and Joseph D., 1996. The NCEP/NCAR 40-Year Reanalysis Project. Bull. Amer. Meteor. Soc. 77, 437-471. DOI: 10.1175/1520-0477(1996)077<0437: TNYRP $>2.0 . \mathrm{CO} ; 2$

KeyserD., Reeder M.J. and Reed R.J., 1988. Ageneralization of Petterssen's frontogenesis function and its relation to the forcing of vertical motion. Mon. Weather Rev. 116, 762-780. DOI: 10.1175/1520-0493(1988)116<0762: AGOPFF $>2.0 . \mathrm{CO} ; 2$

Klimczak C.M., 2000. Diurnal variability and energetics of the North American monsoon: A modeling study. M.Sc. thesis. Department of Meteorology, Florida State University, $93 \mathrm{pp}$.

Krishnamurti T.N., Stefanova L. and Misra V., 2013. Tropical meteorology. An introduction. Springer, 423 pp. DOI: 10.1007/978-1-4614-7409-8
Landsea C.W., 1993. A climatology of intense (or major) Atlantic hurricanes. Mon. Weather Rev. 121, 1703-1713. DOI: 10.1175/1520-0493(1993)121\%3C1703:ACOIMA\%3E2.0.CO;2

Leith C.E., 1981. Dynamically stable nonlinear structures. ECMWF Seminar 1981 on Problems and Prospects in Long and Medium Range Weather Forecasting. ECMWF, Reading, England, 361-370.

Lidy A.M., Cecil M.M., Kunder J. and Packer S.H., 2001. Effectiveness of DoD humanitarian relief efforts in response to hurricanes Georges and Mitch. IDA Paper P-3560, pp. 325

Lindzen R.S. and Nigam S., 1987. On the role of sea surface temperature gradients in forcing low level winds and convergence in the tropics. J.Atmos. Sci., 44, 2418-2436. DOI: $10.1175 / 1520-0469$ (1987)044<2418: OTROSS $>2.0 . \mathrm{CO} ; 2$

Matsuno T., 1966. Quasi-geostrophic motions in the equatorial area, J. Meteor. Soc. Japan, 44, 25-43.

DOI: $10.2151 / j m s j 1965.44 .1 \_25$

Montgomery M.T. and Farrell B.F., 1993. Tropical cyclone formation. J. Atmos. Sci. 50, 285-310. DOI: 10.1175/1520-0469(1993)050<0285:TCF $>2.0 . \mathrm{CO} ; 2$

Neven E.C., 1992. Quadrupole modons on a sphere. Geophys. Astro. Fluid 65, 105-126.

DOI: $10.1080 / 03091929208225242$

Neven E.C., 2001. Linear stability of modons on a sphere. J. Atmos. Sci. 58, 2280-2305.

DOI: $10.1175 / 1520-0469(2001) 058<2280$ :LSO$\mathrm{MOA}>2.0 . \mathrm{CO} ; 2$

Pasch R.J., Avila L.A. and Guiney J.L., 2001. Atlantic hurricane season of 1998. Mon. Weather Rev. 129, 3085-3123.

DOI: 10.1175/1520-0493(2001)129<3085:AHSO >2.0. $\mathrm{CO} ; 2$

Pedlosky, J., 1979. Geophysical fluid dynamics. Springer-Verlag, New York-Heidelberg-Berlin, 626 pp. DOI: 10.1007/978-1-4684-0071-7

Pérez-García I., 1993. Estudios sobre los factores meteorologicos sinopticos y de mesoescala asocia- dos con las intensas lluvias ocurridas a finales de diciembre 1990 en el NO de la Republica Mexicana. Reporte Tecnico-SGA-91-030, SMN-CNA, 229 pp.

Pérez-García I. and Skiba Y.N., 1999. Simulation of exact barotropic vorticity equation solutions using a spectral model. Atmósfera 12, 223-243.

Pérez-García I., 2014. Rossby-Haurwitz perturbation under tropical forcing. Atmósfera 27, 239-249. 
Pérez-García I., 2015. Exact solutions of the vorticity equation on the sphere as a manifold. Atmósfera 28, 179-190. DOI: 10.20937/ATM.2015.28.03.03

Pérez-García I., Aguilar A., Salas A., Meza R. and Gonzales F., 2016. El anticiclón de verano de mayo-junio. XXV Congreso Mexicano de Meteorología. Organización Mexicana de Meteorólogos, Puerto Vallarta, Jalisco, Mexico.

Pérez-García I., Aguilar A. and Hernández J., 2017. Interaction of tropical cyclones with a dipole vortex. In: Vortex structures in fluid dynamic problems (Pérez-de-Tejada H., Ed.). IntechOpen, London. DOI: $10.5772 / 65953$

Reed T.R., 1933. The North American high-level anticyclone. Mon. Weather Rev. 61, 321-325.

DOI: 10.1175/1520-0493(1933)61<321:TNAHA $>2.0$. $\mathrm{CO} ; 2$

Sadler J.C., 1976. A role of the tropical upper tropospheric trough in early season typhoon development. Mon. Weather Rev. 104, 1266-1278.

DOI: 10.1175/1520-0493(1976)104<1266: AROTTU $>2.0 . \mathrm{CO} ; 2$

Sardeshmukh P.D. and Hoskins B.J., 1987. On the derivation of the divergent flow from the rotational flow: The chi problem. Q. J. R. Meteorol. Soc. 113, 339-360. DOI: $10.1002 / \mathrm{qj} .49711347519$

Shapiro L.J., 1987. Month-to-month variability of the Atlantic tropical circulation and its relationship to tropical storm formation. Mon. Weather Rev. 115, 1598-1614. DOI: 10.1175/1520-0493(1987)115<2598:MTMVOT>2.0.CO;2

Sikdar D.N. and Hentz S.J., 1980. Kinematic structure of an Atlantic cloud cluster during GATE and its time variation. Tellus 32, 439-455.

DOI: 10.1111/j.2153-3490.1980.tb00971.x

Simmons A.J., Wallace J.M. and Branstator G.W., 1983. Barotropic wave propagation and instability, and atmospheric teleconnection patterns. J. Atmos. Sci. 40, 13631392. DOI: $10.1175 / 1520-0469(1983) 040<1363$ :BWPAIA $>2.0 . \mathrm{CO} ; 2$
Skiba Y.N. and Pérez-García I., 2009. Numerical spectral method for normal-mode stability study of ideal flows on a rotating sphere. Int. J. Appl. Math. 22, 725-758.

Ting M. and Wang H., 1997. Summertime U.S. precipitation variability and its relation to Pacific sea-surface temperature. J. Climate 10, 1853-1873.

DOI: $10.1175 / 1520-0442(1997) 010<1853$ :SUS$\mathrm{PVA}>2.0 . \mathrm{CO} ; 2$

Tribbia J.J., 1984. Modons in spherical geometry. Geophys. Astro. Fluid 30, 131-168.

DOI: $10.1080 / 03091928408210080$

Verkley W.T.M., 1984. The construction of barotropic modons on a sphere. J. Atmos. Sci. 41, 2492-2504. DOI: $10.1175 / 1520-0469(1984) 041<2492$ :TCOB$\mathrm{MO}>2.0 . \mathrm{CO} ; 2$

Verkley W.T.M., 1987. Stationary barotropic modons in westerly background flows. J. Atmos. Sci. 44, 2383 2398.

DOI: 10.1175/1520-0469(1987)044<2383:SBMIW$\mathrm{B}>2.0 . \mathrm{CO} ; 2$

Verkley W.T.M., 1990. Modons with uniform absolute vorticity. J. Atmos. Sci. 47, 727-745.

DOI: 10.1175/1520-0469(1990)047<0727: MWUAV $>2.0 . \mathrm{CO} ; 2$

Vitart F. and Anderson J.L., 2001. Sensitivity of Atlantic tropical storm frequency to ENSO and interdecadal variability of SSTs in an ensemble of AGCM integrations. J. Climate 14, 533-545.

DOI: 10.1175/1520-0442(2001)014\%3C0533:SOATSF\%3E2.0.CO;2

Wang C., 2007. Variability of the Caribbean low-level jet and its relations to climate. Clim. Dynam. 29, 411-422. DOI: $10.1007 / \mathrm{s} 00382-007-0243-\mathrm{z}$

Wood K.M, and Ritchie E.A., 2013. An updated climatology of tropical cyclone impacts on the southwestern United States. Mon. Weather Rev. 141, 4322-4336. DOI: 10.1175/MWR-D-13-00078.1. 